\title{
Halogens in pore water of peat bogs - the role of peat decomposition and dissolved organic matter
}

\author{
H. Biester ${ }^{1}$, D. Selimović ${ }^{1}$, S. Hemmerich ${ }^{1}$, and M. Petri ${ }^{2}$ \\ ${ }^{1}$ University of Heidelberg, Institute of Environmental Geochemistry, INF 236, 69120 Heidelberg, Germany \\ ${ }^{2}$ Zweckverband Bodensee-Wasserversorgung, Betriebs- und Forschungslabor, Süßenmühle 1, 78354 Sipplingen, Germany
}

Received: 16 August 2005 - Published in Biogeosciences Discussions: 20 September 2005

Revised: 16 December 2005 - Accepted: 22 December 2005 - Published: 27 January 2006

\begin{abstract}
Halogens are strongly enriched in peat and peatlands and such they are one of their largest active terrestrial reservoir. The enrichment of halogens in peat is mainly attributed to the formation of organohalogens and climatically controlled humification processes. However, little is known about release of halogens from the peat substrate and the distribution of halogens in the peat pore water. In this study we have investigated the distribution of chlorine, bromine and iodine in pore water of three pristine peat bogs located in the Magellanic Moorlands, southern Chile. Peat pore waters were collected using a sipping technique, which allows in situ sampling down to a depth greater than $6 \mathrm{~m}$. Halogens and halogen species in pore water were determined by ion-chromatography (IC) (chlorine) and IC-ICPMS (bromine and iodine). Results show that halogen concentrations in pore water are 15-30 times higher than in rainwater. Mean concentrations of chlorine, bromine and iodine in pore water were $7-15 \mathrm{mgl}^{-1}, 56-123 \mu \mathrm{gl}^{-1}$, and $10-20 \mu \mathrm{g}^{-1}$, which correspond to mean proportions of 10 $15 \%, 1-2.3 \%$ and $0.5-2.2 \%$ of total concentrations in peat, respectively. Organobromine and organoiodine were the predominant species in pore waters, whereas chlorine in pore water was mostly chloride. Advection and diffusion of halogens were found to be generally low and halogen concentrations appear to reflect release from the peat substrate. Release of bromine and iodine from peat depend on the degree of peat degradation, whereas this relationship is weak for chlorine. Relatively higher release of bromine and iodine was observed in less degraded peat sections, where the release of dissolved organic carbon (DOC) was also the most intensive. It has been concluded that the release of halogenated dissolved organic matter (DOM) is the predominant mechanism of iodine and bromine release from peat.
\end{abstract}

Correspondence to: $\mathrm{H}$. Biester

(hbiester@ugc.uni-heidelberg.de)

\section{Introduction}

For a long time halogens were seen to behave mostly conservative in the soil and aquatic environment. Today halogens are known to be involved in a large number of biogeochemical mechanisms related to the transformation of organic matter and some of these processes are basic for the understanding of the biogeochemical cycling of halogens. Natural formation of organohalogens in nearly all aquatic and terrestrial environments is widely accepted to be a key mechanism for the retention and enrichment of halogens in soils (Öberg, 2002) and peatlands (Keppler and Biester, 2003; Biester et al., 2004). Enzymatic processes such as haloperoxidases and halogenases are thought to be the major source of natural halogenated organic compounds in the environment (e.g. Shaw and Hager, 1959; Asplund et al., 1993; Gribble, 2003; Van Pée and Unversucht, 2003). Most recent studies on the behavior of halogens in the pedosphere are focused on chlorine while much less is known about the fate of bromine and iodine. Studies on the dynamics of iodine and bromine in soils indicate that both elements form stable organohalogen compounds through interaction with humic substances (Whitehead, 1984; Yuita, 1994) and laboratory studies have also shown that iodine in seepage water from soils and in brown waters from bogs is preferentially bound to humic acids (Rädlinger and Heumann, 2000). Moreover, iodine bound to soluble humic substances has been shown to undergo microbial induced changes, where iodine is bound to different molecular weight fractions of the organic matter during different stages of ageing (Heumann et al., 2000).

Ombrotrophic peat bogs, which receive all elements exclusively through atmospheric deposition, are widely used as environmental archives. Being solely built up by organic matter, they are ideal natural laboratories to study the role of organic matter transformation processes in the biogeochemical cycling of halogens. Data on halogens in peat are still limited to a small number of studies (Chagué-Goff and Fyfe,

(C) 2006 Author(s). This work is licensed under a Creative Commons License. 


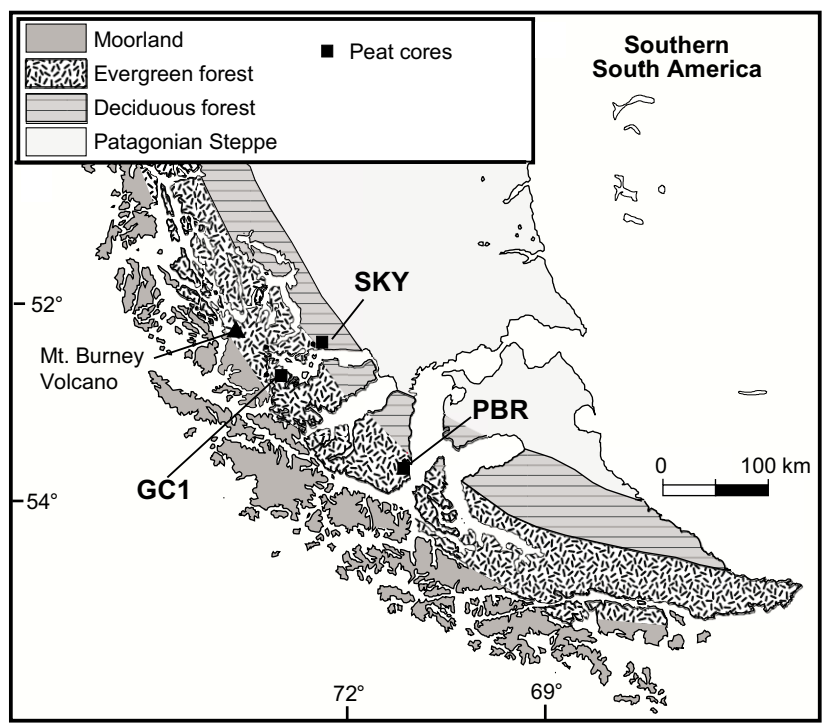

Fig. 1. Locations of the sample sites GC1, SKY, and PBR in the Magellanic Moorlands, Chile.

1996; Maw and Kempton, 1982; Shotyk, 1997; Silk et al., 1997; Keppler and Biester, 2003; Biester et al., 2004).

The major mechanism of halogen retention by peat is the formation of organohalogens (Silk et al., 1997; Keppler and Biester, 2003, Biester et al., 2004). For example, Keppler et al. (2004) demonstrated that peat has a large capacity to retain atmospheric iodine through formation of organoiodine and that mires and bogs are major terrestrial sinks for iodine. Moreover, concentrations of organically bound halogens in peat strongly depend on the degree of peat decomposition (Biester et al., 2004). In this context the highest halogen concentrations in peat were correlated with relatively dry periods, when the bog wetness is lower and peat decomposition is high. Thus, historical records of halogen concentrations in peat bogs do reflect changes in peat decomposition, rather than changes in atmospheric fluxes.

Besides investigations on changes of halogen concentrations or accumulation rates in peat bogs the release of halogens from peat to peat pore water during diagenesis of the organic matter is of major interest in estimating halogens fluxes from peatlands into rivers and streams. Many pore water investigations in peat bogs have been carried out using in situ diffusion equilibrium samplers (peepers) (e.g. BendellYoung and Pick, 1997; Steinmann and Shotyk, 1997) or suction techniques (e.g. Blodau and Moore, 2002). The idea that pore water in bogs reflects the release of solutes from surrounding peat is based on the assumption that water does not flow through the deeper parts of peat bogs because the hydraulic conductivity of many peats is too low (Ingram, 1982). Other studies have shown that climate fluctuations of short duration may temporarily reverse the vertical direc- tion of fluid flow through the peat, which can reverse concentration gradients of pore water solutes (Romanowicz et al., 1993; Fraser et al., 2001). On the other hand, longer periods (3-5 years) of droughts can produce significant changes in pore water chemistry (Siegel et al., 1995).

Only a small number of studies have focused on the fate of halogen in peat bogs. Shotyk (1997) has investigated halogens in peat and pore water in two bogs in Scotland and concluded that chlorine is conservative in bogs, whereas bromine is not. However, these investigations were focused on inorganic halogen species and did not consider organohalogen compounds in pore water or the role of dissolved organic matter released from peat.

Mechanisms of halogen release from organic substrates have been predominantly investigated as a remediation technique for groundwater contaminated with chlorinated organic solvents or other specific pollutants. In contrast little is known about dechlorination of natural formed organohalogens. Laboratory studies have shown that dehalogenation can occur under aerobic and anaerobic conditions and that halogens are cleaved enzymatically from the organic substrate. An overview on dechlorination mechanisms can be found in Winterton (2000) and in Van Pée and Unversucht (2003). However, natural mechanisms of formation and dehalogenation of organobromine and organoiodine compounds in peat bogs are mostly unknown.

As a first step to understand the fate of halogens in bogs we investigated the distribution and speciation of halogens in pore water at three bog sites located in the Magellanic Moorlands, Chile. Based on data of peat decomposition obtained during previous studies we investigated here the degree halogen release from peat and its dependence on the degree of peat humification or the release of dissolved organic matter (DOM).

\section{Methods and materials}

\subsection{Sampling locations}

Pore water samples were collected from three ombrotrophic bogs (GC1, SKY and PBR) located in different climatic zones of the Magellanic Moorlands, southernmost Chile (Fig. 1). The GC1 bog is a cushion plant bog, which is typical for the super-humid area (S 52 $47.443^{\prime} / \mathrm{W} 72^{\circ} 56.616^{\prime}$ ). The bog is characterized by intense atmospheric deposition of sea-salt aerosols due to the high precipitation rates in this area $\left(>6000 \mathrm{~mm} \mathrm{yr}^{-1}\right)$ (Schneider et al., 2003). SKY is a raised bog located in the transition zone between the extremely humid zone of the Magellanic Moorlands and the dry Pampa grasslands (precipitation rates $<500 \mathrm{~mm} \mathrm{yr}^{-1}$ ) (S $\left.52^{\circ} 30.668^{\prime} / \mathrm{W} 72^{\circ} 07.505^{\prime}\right)$. Precipitation rates at the SKY location (1000-1500 $\mathrm{mm} \mathrm{yr}^{-1}$ ) are much lower than at the GC1 location and previous studies on peat humification have shown periodically dry falling of the bog's surface (Biester 
et al., 2003). The PBR bog is a typical raised Sphagnum bog located on Peninsula Brunswick at the Strait of Magellan (S $53^{\circ} 38.281^{\prime} / \mathrm{W} 70^{\circ} 58.029^{\prime}$ ). One or more tephra layers were found in all three bogs, which can be assigned to different eruptions of the volcanoes Mt. Burney, Hudson and Reclus, all located in the southern Andes (Kilian et al., 2003). A detailed discussion of the ombrotrophic nature of the bogs and geochemical characteristics of the peat is given elsewhere (Biester et al., 2003).

\subsection{Sampling of pore waters}

Pore waters in peat bogs are usually collected by means of in situ diffusion equilibrium samplers (peepers), which allow collection of interstitial waters. In other studies sipping techniques have been proposed to collect pore water from peat (Romanowicz et al., 1993; Blodau and Moore, 2002). In our study we used a self-constructed device, which allows pore water sampling down to a depth of $>6 \mathrm{~m}$ by sipping. The device consists of a sampling head and extension rods all made of aluminium (Fig. 2). The sampling head contains an intermediate perforated $(\varnothing 1-5 \mathrm{~mm})$ Teflon ring, which allows lateral inflow of surrounding pore waters. The pore water flowing into the sampling head is collected into a $50 \mathrm{ml}$ polypropylene centrifuge tube (Fig. 2). All parts inside the sampling head, which come in contact with inflowing pore water, are made of Teflon or polypropylene. The perforated Teflon ring can be closed or opened by a movable steel ring, which is connected to a threaded bar inside the extension rods. The openings in the sampling head can be opened or closed from the bog surface by turning the threaded bar by means of a crank handle (Fig. 2). After the head has been positioned at the required sampling depth the inlet is opened and pore waters are allowed to flow into the centrifuge tube for 5-30 min. The openings are then closed and the sampler is pulled out. The threaded bar is connected to a silicon plug which seals the sample tube when the sampling head is closed. The tube was removed from the sampling head and closed. Yields of pore water varied between 10 and $50 \mathrm{ml}$ depending on pore water flow, which was lowest in deeper bog sections. Pore water samples were taken in $15 \mathrm{~cm}$ depth increments. The holes for pore water sampling were located about $20 \mathrm{~cm}$ next to the holes where the peat cores were extracted. Pore water samples were filtered $(0.2 \mu \mathrm{m})$ and stored cold $\left(4^{\circ} \mathrm{C}\right)$ until analyses.

\subsection{Sampling of rainwater}

Rainwater was collected using a $50 \times 40 \mathrm{~cm}$ polypropylene box connected to a $1 \mathrm{~L}$ Teflon bag. Collection was during the October 2002 and March 2003 campaigns; the period of collection was two days at location GC1 and approximately one week at the SKY location. Precipitation rates at the two locations were measured by an automatic-weather stations at each site over a period of one year. (Schneider et al., 2003).

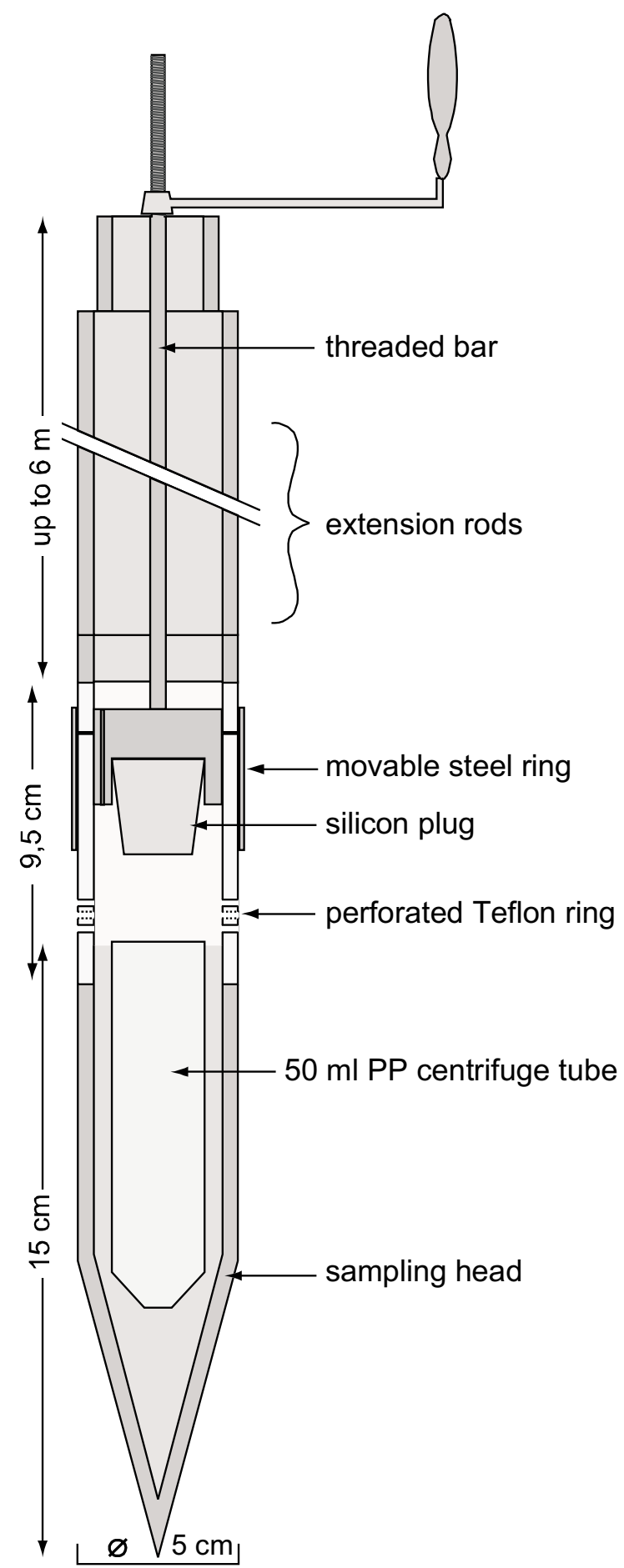

Fig. 2. Sampling device to collect pore water in deep peat layers by sipping.

\subsection{Sampling of peat cores}

Peat profiles were collected at the highest elevation of each bog, where hummocks and hollows, and trees were 
absent. The uppermost $2 \mathrm{~m}$ of the peat was sampled using a $10 \times 10 \times 200 \mathrm{~cm}$ stainless steel Wardenaar-type corer. Deeper sections were sampled with a stainless steel russiantype barrel corer with a $50 \times 5 \mathrm{~cm}$ cylindric sample chamber. All cores were sectioned in the field and placed into polyethylene bags. The GC1 core was sectioned into $2-\mathrm{cm}$ slices while the SKY core was sectioned into 4-cm slices. A layer of about $1 \mathrm{~cm}$ was cut off from each side of the core to avoid cross contamination due to smearing of material from the tephra layers. All samples were stored frozen. Half of each sample was freeze-dried and milled using a titanium centrifuge mill.

\subsection{Differential analysis of halogens in peat}

To distinguish inorganic and organically bound halogens in peat, inorganic halogens were removed prior to combustion by washing the sample with ultra pure water, acidified to $\mathrm{pH}$ 2 with concentrated nitric acid. Concentrations of chlorine, bromine and iodine in untreated peat were determined after combustion of the peat samples (10-25 $\mathrm{mg}$ ) and halogen trapping using an AOX-analyzer (ECS 1000, Thermo Instruments GmbH, Germany). Halogens were then determined by means of ion-chromatography, where chloride was detected through conductivity (Dionex, Germany), and bromide and iodide by UV/VIS absorption (Shimazu, Japan). Halogen concentrations in the washed samples gave the amount of organically bound halogens. The differences in halogen concentrations between untreated and washed samples gave the amount of inorganic halogens. A detailed description of the method is given by Putschew et al. (2003).

\subsection{Determination of carbon, and nitrogen in peat}

Carbon and nitrogen concentrations were determined by means of a C/N-Analyzer (ELEMENTAR) burning 10$20 \mathrm{mg}$ sample aliquots in a tin capsule. Mean relative standard deviations (RSDs) for the determination of carbon and nitrogen were $2.2 \%$ and $2.1 \%$, respectively $(n=3)$.

2.7 Determination of halogens and dissolved organic carbon in rain and pore water

Total chloride in pore water and rainwater was determined by means of ion-chromatography and chloride detection through conductivity (Dionex, Germany). Total bromine and iodine in rain and pore water was analyzed by ICPMS (Perkin-Elmer/Sciex Elan 6100 ICP-MS). In contrast to previous studies (Biester et al., 2004), Rhenium instead of ${ }^{103}$ Rhodium was used as an internal standard for bromine and iodine analysis by ICP-MS as the Rhodium signal shows interferences dependent on DOC concentrations in pore water. Analyses of inorganic bromine and iodine species were performed by IC-ICP-MS using a Dionex IonPac AS9HC $(250 \times 4 \mathrm{~mm})$ column and a AS9GC $50 \times 4 \mathrm{~mm})$ guard col- umn. $\mathrm{Na}_{2} \mathrm{CO}_{3}(20 \mathrm{mmol})$ was used as an eluent at a flow rate of $0.9 \mathrm{ml} / \mathrm{min}$ according to the method of Sacher et al. (1999).

Measurements of bromine and iodine were validated by comparison to a certified reference sample (CRM 611). All measurements of total bromine and iodine (indicative values) and bromide and iodide were in the range of the certified (indicative) values. Amounts of organobromine and organoiodine in pore water were calculated as the difference between total concentrations and the sum of concentrations of inorganic species determined by IC-ICP-MS, respectively.

Dissolved organic carbon (DOC) in pore water was determined in the filtered samples using a Shimadzu TOC 5000 analyzer.

\section{Results and discussion}

\subsection{Halogens in rain}

A major purpose of this study was to evaluate the extent to which halogen concentrations in pore water of peat bogs reflect atmospheric deposition and the release of halogens during decomposition of the organic substrate.

Halogen concentrations in rain were determined at the $\mathrm{GC} 1$ and the SKY location, where weather stations have been operational since 1999 (Schneider et al., 2003). Concentrations and deposition rates of halogens at the two locations are given in Table 1. At GC1 and SKY, 84 and $60 \%$ of the total iodine in rainwater, respectively, was iodide; the remainder was an unidentified, assumingly organic iodine species (Biester et al., 2004). Halogen data in rain from the PBR location were not available. Deposition rates of chlorine, bromine and iodine at the $\mathrm{GC} 1$ site were by factors of 5, 4 and 2.6, respectively, higher than at SKY, which is attributed to higher precipitation rates at the GC1 location (super-humid site). Retention of chlorine in peat ranged between 0.2 and $2.0 \%$, whereas bromine and iodine show much higher retention of 30 to $50 \%$ of wet halogen deposition. A detailed description and discussion of the halogen data in rain and peat at the two bogs can be found in Biester et al. (2004).

\subsection{Halogens in pore water}

The mass balance of halogen, especially of chlorine, in soils is mainly controlled by inputs of atmospheric deposition and losses by surface runoff, evapotranspiration and transport to the groundwater. Enrichment of chlorine in soil solution or groundwater compared to rainwater is mainly attributed to evapotranspiration. Retention of chlorine in soils through the formation of organochlorines or release of chloride during organic matter decay has been reported (Asplund et al., 1989; Flodin et al., 1997) but is of minor importance for the overall budget of chlorine in soil solution. Data on bromine or iodine budgets in soils or peat bogs could not be found in the literature. 
Table 1. Mean total concentrations of halogens in rain, pore water and peat, atmospheric deposition rates, proportions of released halogens and DOC from peat (expressed as percent of total halogens and carbon concentrations in peat).

\begin{tabular}{|c|c|c|c|c|c|}
\hline & $\begin{array}{c}\mathrm{Cl}\left(\mathrm{mg} \mathrm{l}^{-1}\right) \\
\text { Mean }\end{array}$ & $\begin{array}{c}\operatorname{Br}\left(\mu \mathrm{gl}^{-1}\right) \\
\text { Mean }\end{array}$ & $\begin{array}{c}\mathrm{I}\left(\mu \mathrm{g} \mathrm{l}^{-1}\right) \\
\text { Mean }\end{array}$ & $\begin{array}{c}\text { DOC }\left(\mathrm{mg} \mathrm{l}^{-1}\right) \\
\text { Mean }\end{array}$ & $\begin{array}{l}\mathrm{C} / \mathrm{N} \\
\text { Mean }\end{array}$ \\
\hline \multicolumn{6}{|l|}{ Rain } \\
\hline $\mathrm{GC} 1$ & 0.5 & 3.9 & 0.48 & n.d. & I \\
\hline SKY & 0.4 & 3.8 & 0.68 & n.d. & l \\
\hline PBR & n.d. & n.d. & n.d. & n.d. & l \\
\hline Deposition rates ${ }^{\mathrm{a}}$ & $\mathrm{mg} \mathrm{m}^{-2} \mathrm{yr}^{-1}$ & $\mathrm{mg} \mathrm{m}^{-2} \mathrm{yr}^{-1}$ & $\mathrm{mg} \mathrm{m}^{-2} \mathrm{yr}^{-1}$ & $\mathrm{mg} \mathrm{m}^{-2} \mathrm{yr}^{-1}$ & \\
\hline GC1 & 3000 & 23.4 & 2.6 & n.d. & I \\
\hline SKY & 600 & 5,7 & 1 & n.d. & I \\
\hline PBR & n.d. & n.d. & n.d. & n.d. & I \\
\hline Pore water & $\begin{array}{c}\mathrm{Cl} \\
\left(\mathrm{mg} \mathrm{l}^{-1}\right) / \%\end{array}$ & $\begin{array}{c}\mathrm{Br} \\
\left(\mu \mathrm{g}^{-1}\right) / \%\end{array}$ & $\begin{array}{c}\mathrm{I} \\
\left(\mu \mathrm{g} \mathrm{l}^{-1}\right) / \%\end{array}$ & $\begin{array}{c}\text { DOC } \\
\left(\mathrm{mg}^{-1}\right) / \%\end{array}$ & \\
\hline GC1 & $15 / 8$ & $122 / 0.5$ & $6.8 / 0.54$ & 22/0.03 & \\
\hline SKY & $4 / 11$ & $47 / 1$ & $11 / 1.1$ & $48 / 0.1$ & \\
\hline PBR & $10 / 15$ & $97 / 2.2$ & $21 / 2.1$ & $42 / 0.1$ & \\
\hline Peat & $\mathrm{Cl}\left(\mathrm{mg} \mathrm{kg}^{-1}\right)$ & $\mathrm{Br}\left(\mathrm{mg} \mathrm{kg}^{-1}\right)$ & $\mathrm{I}\left(\mathrm{mg} \mathrm{kg}^{-1}\right)$ & & $\mathrm{C} / \mathrm{N}$ \\
\hline GC1 & 1065 & 158 & 16 & & 27 \\
\hline SKY & 405 & 48 & 10 & & 48 \\
\hline PBR & 596 & 60 & 13 & & 58 \\
\hline
\end{tabular}

n.d. = not determined

${ }^{a}=$ data from Biester et al. (2003)

The fate of halogens in bogs is controlled by evapotranspiration, retention by the organic substrate and losses through outflow. Water movement in ombrotrophic bogs is characterised by a large differences in hydrological conductivity between the acrotelm and the catotelm. In the acrotelm hydrological conductivity is usually high, whereas the catotelm is seen to be mostly impermeable (Ivanov, 1981). As such, vertical transport of solutes within peat bogs is generally low and surface runoff and lateral transport through the acrotelm are the dominant hydrological processes controlling advective transport of atmospherically derived solutes (Ingram, 1983; Succow and Joosten, 2001). In this study evapotranspiration and outflow at our study sites were not determined. Due to the necessarily positive water balance of ombrotrophic mires strong enrichment of solutes as a result of evapotranspiration is unlikely to occur.

In the GC1 and the SKY bogs, mean halogen concentrations in pore water were on average a factor of 15-30 higher than in rainwater (Table 1). The largest difference (factor of $\sim 30$ ) between rain and pore water concentrations was found for chlorine and bromine at the GC1 site. At the SKY bog the difference in chlorine and bromine concentrations between rain and pore water was only about half of what was found at the GC1 site. Iodine shows a similar enrichment factor in pore water of $(\sim 20)$ at both sites (Table 1$)$. The higher en- richment factors of halogens in pore water of the $\mathrm{GC} 1$ bog are mainly attributed to the generally higher halogen deposition rates at this site and the resulting higher concentrations of halogens in peat (Biester et al., 2004). Additional inputs by fog or dry deposition, as suggested in other studies (Shotyk, 1997), are assumed to be of minor importance at the Magellanic Moorlands, especially at the GC1 site, where precipitation rates are constantly high throughout the year $(6000$ $10000 \mathrm{~mm} \mathrm{yr}^{-1}$, Schneider et al., 2004). Such high enrichment of halogens in peat pore water of living bogs could not be explained by evapotranspiration alone. If the enrichment of halogens in pore water is solely a result of evapotranspiration, halogen ratios in rain and pore water should be similar. Although mean molar ratios of $\mathrm{Cl} / \mathrm{Br}, \mathrm{Cl} / \mathrm{I}$ and $\mathrm{Br} / \mathrm{I}$ are similar to those found in rain (Table 2), the wide range of variation indicates that concentrations in pore water are influenced by halogen release from peat. On the other hand halogen ratios in pore water were significantly higher than those found in peat indicating that the intensity of release from peat is different for the three halogens (Table 2).

\subsection{Variability of halogen concentrations in pore water}

The interpretation of halogen concentrations in pore water is based on the principal model that element concentrations in 


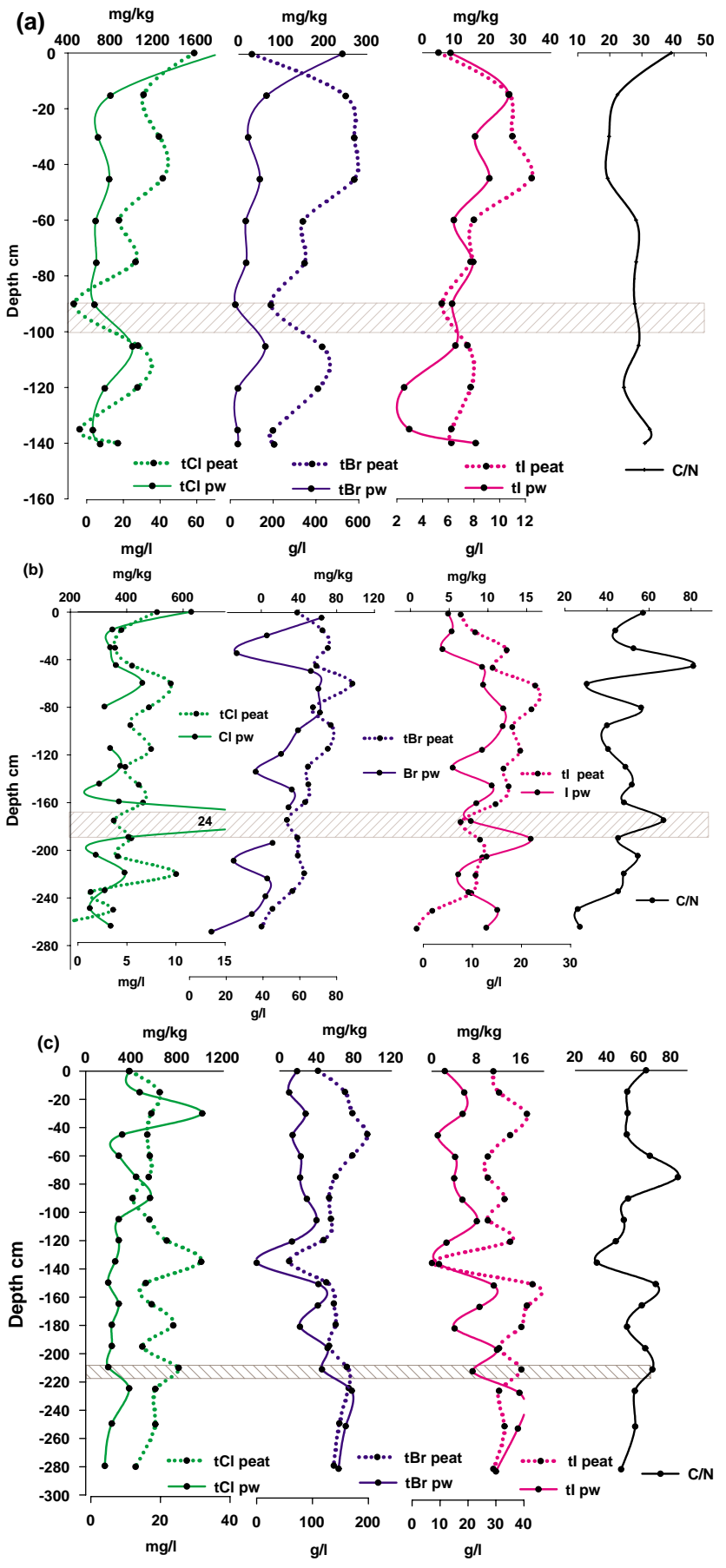

Fig. 3. Total halogen concentrations $(\mathrm{tCl}, \mathrm{tBr}, \mathrm{tI})$ in peat and pore water (pw) in three ombrotrophic peat bogs GC1 (a), SKY (b), PBR (c) located in the Magellanic Moorlands compared to $\mathrm{C} / \mathrm{N}$ ratios indicating differences in the degree of peat decomposition. Gray bars indicate tephra layers.

the pore water of sediments are mainly controlled by porosity, advection, diffusion and release (production) from the substrate (Berg et al., 1998; Blodau and Moore, 2003). Ad- vection is known to be high in the acrotelm due to its high effective macroporosity (Fraser et al., 2001). In contrast, hydrological conductivity and vertical transport of solutes in the catotelm are generally low and therefore the major factors controlling distribution of solutes in pore water in the catotelm is diffusion and release from the substrate.

Concentrations of halogens in pore water show intense changes and large concentration gradients throughout the peat profiles (Fig. 3). The largest variations in halogen concentrations were found in the GC1 core, where values vary by factors of 16 to 22 . The high gradients are only found for chlorine and bromine in the uppermost peat layer and release of $\mathrm{Cl}$ and $\mathrm{Br}$ in the early phase of plant material decay (Fig. 3a) was assumed to be the primary mechanism for this enrichment. However, such high concentrations of chlorine and bromine in the upper peat section could not be observed in the other two bogs (Figs. 3b, c). We assume that the cushion plants, which are dominant in the GC1 bog, contain larger amounts of chlorine and bromine than Sphagnum mosses, which are dominant in SKY and PBR peat.

Despite the chlorine and bromine enrichment in the surface layer changes in halogen concentrations are more frequent and more pronounced in the SKY and the PBR bogs, especially for bromine and iodine (Fig. 3). Here, concentrations of chlorine, bromine and iodine vary by factors of up to 16 (Tephra) and 8, up to 6 and 3 and up to 4 and 6 , respectively.

The high concentration gradients observed indicate that diffusion, especially in the acrotelm, is very low. Information on the size of ions or molecules is crucial for diffusion processes in porous media as diffusion coefficients of small ions or molecules are higher than those of large ones. For example, diffusion of large humic molecules in aqueous solution has been shown to be very low $\left(\sim 1.35 \times 10^{-10} \mathrm{~m}^{2} \mathrm{~s}^{-1}\right.$ for humic acid molecules of 10000 to $100000 \mathrm{~g} \mathrm{~mol}^{-1}$ ) (Cornel et al., 1986) compared to small ions such as chloride, which show effective diffusion coefficients in the range of $\sim 2 \times 10^{-6} \mathrm{~m}^{2} \mathrm{~s}^{-1}$ in porous media (Appelo and Postma, 1996).

The speciation measurements of bromine and iodine show that $51-69 \%$ of bromine and $88-93 \%$ of iodine in pore water exists in organic forms (soluble organohalogens or halogenated dissolved humic substances). Organochlorine compounds in pore water were not determined in this study. Their concentrations in lakes and rivers can range between 11 and $185 \mu \mathrm{gl}^{-1}$, and highest values were found in streams draining peatlands (Asplund, 1991). Moreover, fulvic acids play an important role in transport of organochlorine in the environment by binding of chlorine to aromatic structures (Dahlmann et al., 1993). Assuming that similar amounts of organochlorine occur in peat pore water less than $1.4-3 \%$ of total chlorine in pore water would exist as organochlorines. Thus, the occurrence of such high amounts of organically (humic) bound bromine and especially iodine and the very low diffusion coefficients of dissolved humic substances 
Table 2. Molar ratios of halogens in rainwater, peat and pore water collected at the locations GC1, SKY, and PBR.

\begin{tabular}{lccc}
\hline & $\begin{array}{c}\mathrm{Cl} / \mathrm{Br} \\
\text { mean/range }\end{array}$ & $\begin{array}{c}\mathrm{Cl} / \mathrm{I} \\
\text { mean/range mean/range }\end{array}$ & $\mathrm{Br} / \mathrm{I}$ \\
\hline GC1 (rainwater) & 289 & 3734 & 13 \\
SKY (rainwater) & 235 & 2108 & 9 \\
& & & $29 / 6-137$ \\
GC1 (pore water) & $293 / 152-624$ & $8576 / 1117-42735$ & $9 / 1.5-33$ \\
SKY (pore water) & $257 / 80-750$ & $2541 / 290-12699$ & $7 / 5-11$ \\
PBR (pore water) & $262 / 62-825$ & $2072 / 478-6355$ & \\
& & & $22(7.7) / 3.8-166$ \\
GC1 (peat) & $32 / 7-67$ & $305(222) / 135-1130$ & $7.4 / 0.46-12.3$ \\
SKY (peat) & $58.7 / 11-674$ & $176 / 100-446$ & $7.7 / 4-12$ \\
PBR (peat) & $32.6 / 12-227$ & $157 / 104-200$ & \\
\hline
\end{tabular}

can explain why the diffusion of bromine and iodine in our profile is so low and concentration gradients are high. Organochlorine seems to be of minor importance for the distribution of chlorine in our bogs and chloride is the predominant species in pore water. The comparatively high diffusion coefficients of chloride (compared to humic acid bound chlorine) explain the smoother concentration gradients of chlorine in our bogs compared to those of bromine and iodine.

\subsection{Relationship between halogen concentrations in peat and pore water}

The observation of high concentration gradients and low diffusion of bromine and iodine implies that concentrations in pore water are indicative for release of these halogens from the peat substrate and that release intensities are different in individual peat layers. One reason for the variations in halogen release throughout the peat profile could be differences in halogen concentrations in peat, which are generally high in all three bogs (Table 1). Moreover, as they occur predominately as organohalogens their concentrations are to a large extent determined by the degree of peat decomposition (Biester et al., 2004) and thus show large variations within the peat profiles (Fig. 3). However, a clear relationship between total halogen concentrations in peat and in pore water could not be found. In general, profiles of chlorine concentrations in pore water show different patterns than bromine and iodine (Fig. 3). In all three bogs, chlorine concentrations in pore water show a tendency to follow concentrations in peat. This trend is comparatively clear in the GC1 profile (Fig. 3a), but weaker, or nearly absent in the SKY and PBR profiles (Figs. 3b, c). Bromine and iodine concentrations in the SKY and PBR pore water profiles tend to be inversely related to concentrations in peat, whereas this trend could not be observed in the GC1 profile, where bromine and iodine concentrations in pore water also seem to follow their concentrations in peat in some sections of the core (Fig. 3a). However, comparison of halogens in pore water and peat on a concentration basis does not consider variation of peat mass per volume. Therefore, halogen concentrations in pore water and peat must be compared on a mass per volume basis if halogen concentrations in pore water are considered as proportions of halogens released from peat.

\subsection{Halogen release from peat}

Proportions of released halogens were calculated by relating the amount of halogens in 11 of pore water to the amount of halogens in the mass of peat in the same volume. The use of the term release implies that all halogens found in pore water are released from peat and neglects halogens enrichment as a result of evapotranspiration. It is clear that halogens are enriched by evapotranspiration but the high halogen concentrations in peat and the high enrichment factors compared to rainwater concentrations indicate that the enrichment of halogens in pore water is mainly attributed to release from peat and evapotranspiration only plays a minor role.

Due to its high water content $(\sim 80-95 \%)$ the mean mass of solid matter in a volume of 1 litre of fresh peat was only $60-150 \mathrm{~g}$. In all three bogs proportions of chlorine in pore water $(10-15 \%)$ are by a factor of 7 to $\sim 10$ higher than those of bromine or iodine $(0.5-2.1 \%)$, which show similar values (Table 1). This suggests that different release mechanisms of chlorine compared to bromine and iodine control the enrichment of the three halogens in pore water.

As conditions in the catotelm are anaerobic, reductive dehalogenation is expected to be one of the potential mechanisms of halogen release from peat. In fact the predominance of chloride in pore water suggests that reductive dehalogenation is indeed the predominant mechanism of the chlorine release from peat. Sorption and desorption mechanisms of halogens, especially of bromine and iodine, to and from humified organic matter, particularly under anoxic conditions, is not well investigated. From the physical and chemical characteristics of the three halogens, such as ionic radii and the polarity of the carbon halogen bonds, we 
expected that dehalogenation of organic matter proceeds in the order iodine, bromine and chlorine. Studies on dehalogenation mechanisms in anaerobic sediments have demonstrated that e.g. brominated biphenyls are better dehalogenation substrates than chlorinated biphenyls (Bedard and Van Dort, 1998). Studies on spiked organic rich sediments have shown that iodine is immobile under oxic condition but released from the sediment under unoxic conditions (Bird and Schwartz, 1996). However, as most bromine and iodine in our pore water samples exist as organohalogens we concluded that reductive dehalogenation is of minor importance for the release of bromine and iodine in anaerobic peat and that the release of both halogens is more likely to be dependent on the release of DOM.

3.6 Release of halogens and DOC and the role of peat decomposition

Dynamics of DOM in soils are closely related to decomposition, humification and stabilization of organic matter (Zech et al., 1997). Kalbitz and Geyer (2002) could show that DOM release from peat is related to the degree of peat decomposition and decreases with increasing humification. To understand the relationship between peat decomposition and the release of DOC and halogens in bogs it must be kept in mind that the degree of decomposition is determined at the time of peat formation in the acrotelm and this degree of decomposition is preserved when the peat enters the catotelm (Malmer and Wallén, 2004). Decomposition of organic matter in the acrotelm is mainly controlled by oxygen supply, water table fluctuations and peat growth rates. Humification processes occurring in the anaerobic zone (catotelm) are slow if compared to decomposition in the acrotelm. Accordingly, the degree of humification in the catotelm predominately reflects the hydrochemical conditions (especially bog wetness) at the time of peat formation at the bogs surface; hundred to thousands of years ago.

Assuming that there is no significant vertical downward transport in the catotelm and that advective movement of pore water solutes in the catotelm is negligible concentrations of halogens in pore water reflect the present day equilibrium between peat and pore water. However, Siegel et al. (1995) could show that severe droughts $(>3-5$ years) can have strong effects on the exchange of pore water in bogs due to large changes in water table mounds. From this, Siegel et al. (1995) concluded that the chemical composition of bog waters might not truly reflect the long-term hydrological state of bogs, but rather a transient climate signal that occurs several years before the time of pore water sampling. The effects of dry-falling are not important for the pore water chemistry of the GC1 and PBR bogs, but may have occurred at the SKY bog, where periodical dry-falling events have been deduced from peat decomposition patterns (Biester et al., 2003, 2004).

As conducted in other studies, we used carbon/nitrogen ratios $(\mathrm{C} / \mathrm{N})$ as a measure of the degree of peat humifica- tion or rather decomposition (reflecting also mineralization) and changes in mass loss to evaluate the influence of peat decomposition. Low ratios indicate high humification and vice versa (Malmer and Wallén, 1993; Kuhry and Vitt, 1996; Biester et al., 2004). The degree of peat decomposition, as expressed by $\mathrm{C} / \mathrm{N}$ ratios (means) is similarly low in the SKY and the PBR bogs (high $\mathrm{C} / \mathrm{N}$ : 48 and 58), but significantly higher (low $\mathrm{C} / \mathrm{N}$ : 27) in the GC1 bog (Table 1).

Mean concentrations and mean proportions of released DOC (related to total carbon in peat) are similar high in SKY (48 $\left.\mathrm{mgl}^{-1}, 0.11 \%\right)$ and PBR $\left(41 \mathrm{mg} \mathrm{l}^{-1}, 0.1 \%\right)$ pore water, but are by a factor of $\sim 2.5$ lower in GC1 pore water (22 $\left.\mathrm{mg} \mathrm{l}^{-1}, 0.04 \%\right)$, which reflects the generally higher degree of peat decomposition of GC1 peat (Table 1). Similarly to bromine and iodine, DOC concentrations in the SKY and PBR bogs show large gradients throughout the profile with changes in concentrations by more then a factor of 2 (Fig. 4). As discussed for the organohalogens, the reason for this steep gradients is the very low diffusion of large organic macromolecule such as humic or fulvic acids in aqueous solutions (Cornel et al., 1986). Thus, DOC concentrations in pore water predominately reflect DOM production and release from peat.

Concentrations of DOC in the bogs show only a vague relationship with peat decomposition patterns $(\mathrm{C} / \mathrm{N})$. However, if proportions of released DOC are compared to $\mathrm{C} / \mathrm{N}$ ratios a clearer dependency of DOC release from the degree of peat decomposition can be observed (Fig. 4). This relationship is pronounced in the SKY and the PBR bogs, where proportions of released DOC follow $\mathrm{C} / \mathrm{N}$ ratios in most parts of the profiles (Figs. 4b, c) indicating that relatively more DOC is released from low degraded peat (high $\mathrm{C} / \mathrm{N}$ ratios) and vice versa. In GC1 DOC concentrations and also proportions of released DOC peat show no clear relationship with peat decomposition (Fig. 4a), which we attribute to the low variation and the generally high and uniform degree of peat decomposition in this bog.

The occurrence of high amounts of soluble organobromine and organoiodine compounds in pore water substantiates the relationship between the release of DOC and that of bromine and iodine. This relationship is pronounced in the SKY and the PBR profiles, where proportions of released bromine and iodine are in phase with proportions of released DOC and also with $\mathrm{C} / \mathrm{N}$ ratios in most parts of the profiles (Figs. $4 \mathrm{~b}$, c). However, in the upper sections of the SKY and the PBR profiles (in the section of present day water table fluctuation) the relationship between peat decomposition, DOC and halogen release seems to be weak, or absent. The upper $50-70 \mathrm{~cm}$ of those cores consist of only slightly decomposed plant litter with a high active porosity and macro-pore openings adjacent to roots, which can at least locally increase the hydraulic conductivity. Thus, halogen, or DOC concentrations in this section give rather average values of the whole section than of individual peat slices. 
(a) $\mathrm{mg} / \mathrm{LOC}$
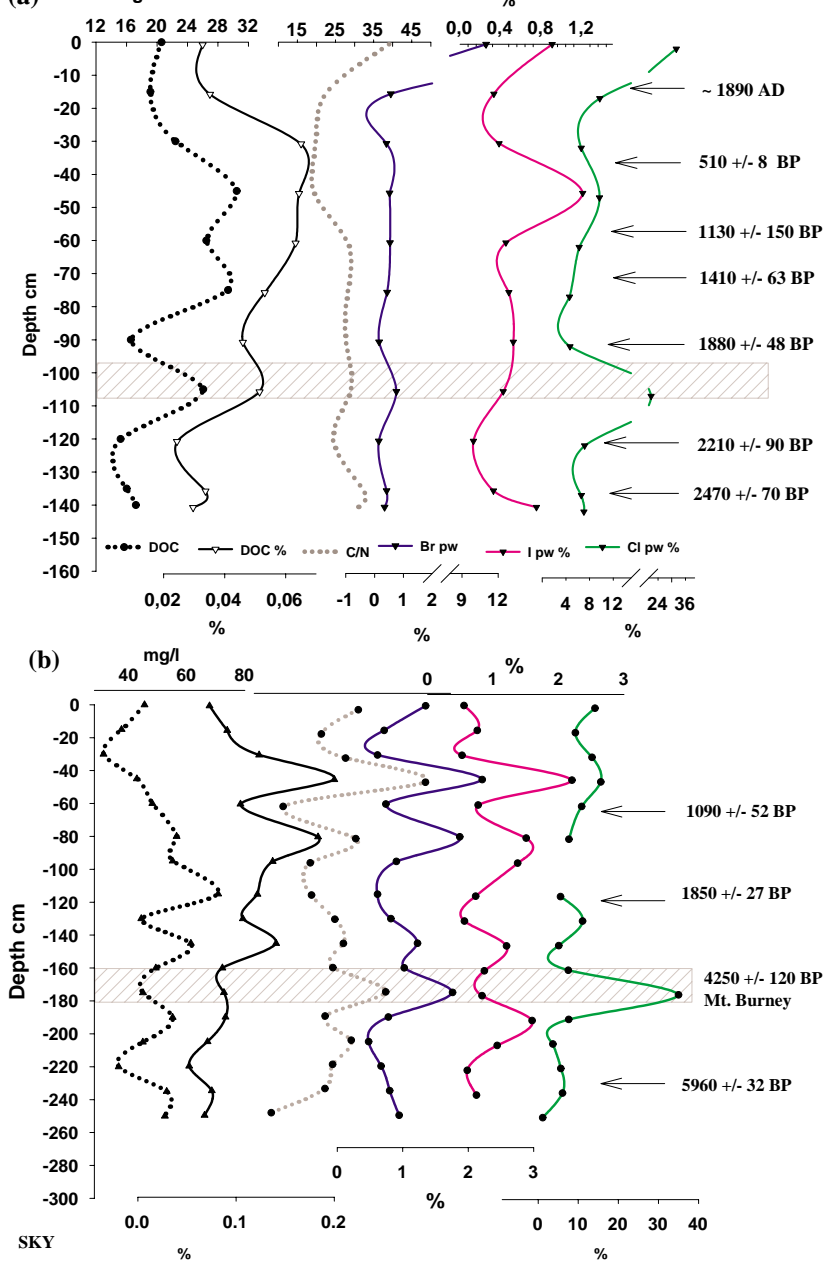

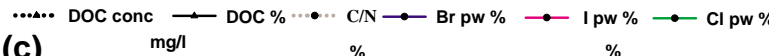

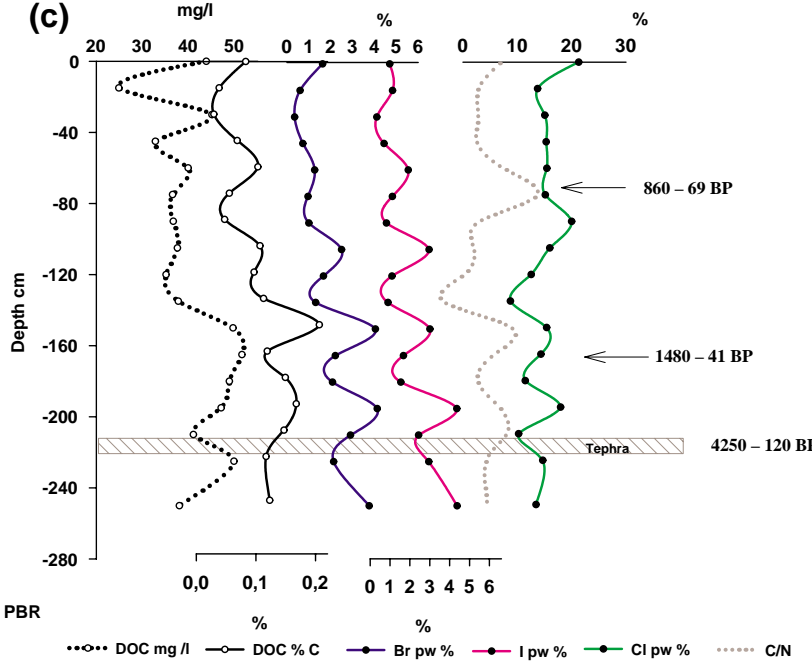

Fig. 4. Concentrations of DOC in pore water and proportions of DOC, chlorine, bromine and iodine released from peat in the peat bogs GC1 (a), SKY (b), PBR (c) located in the Magellanic Moorlands. Gray bars indicate tephra layers. (a)
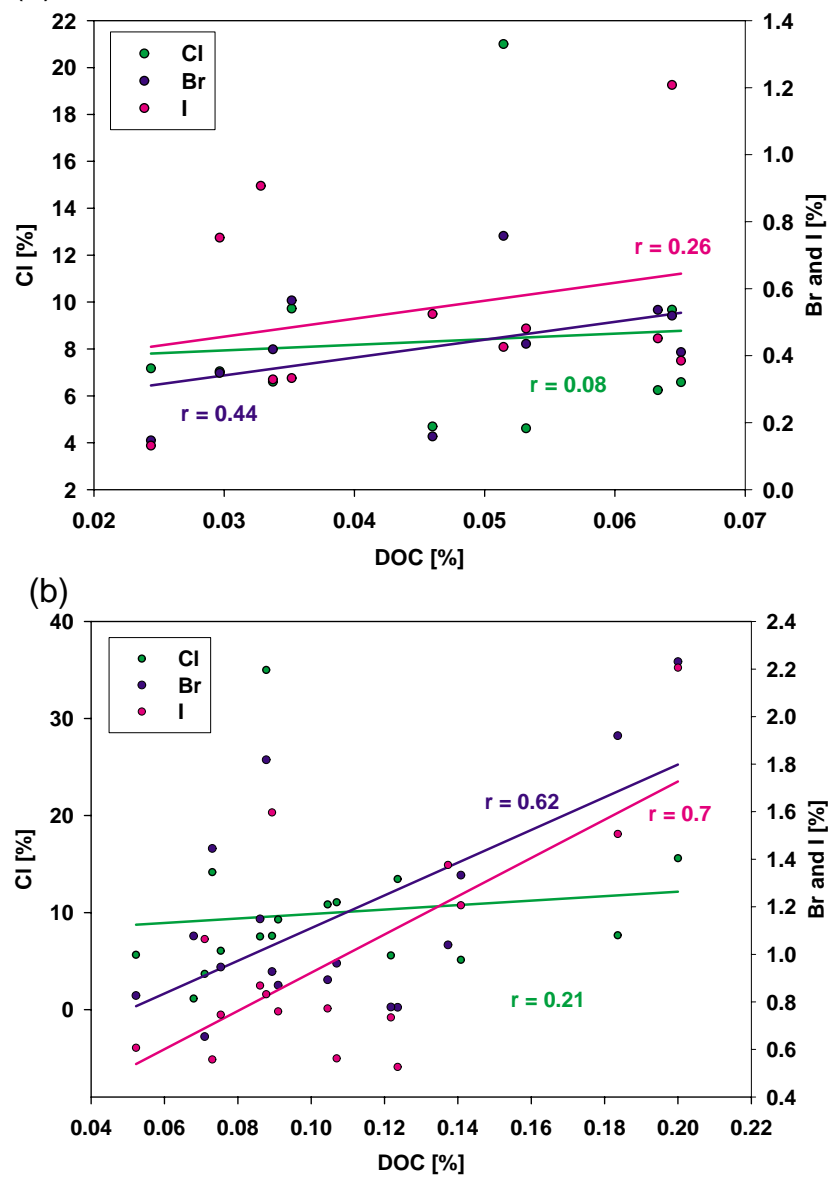

(c)

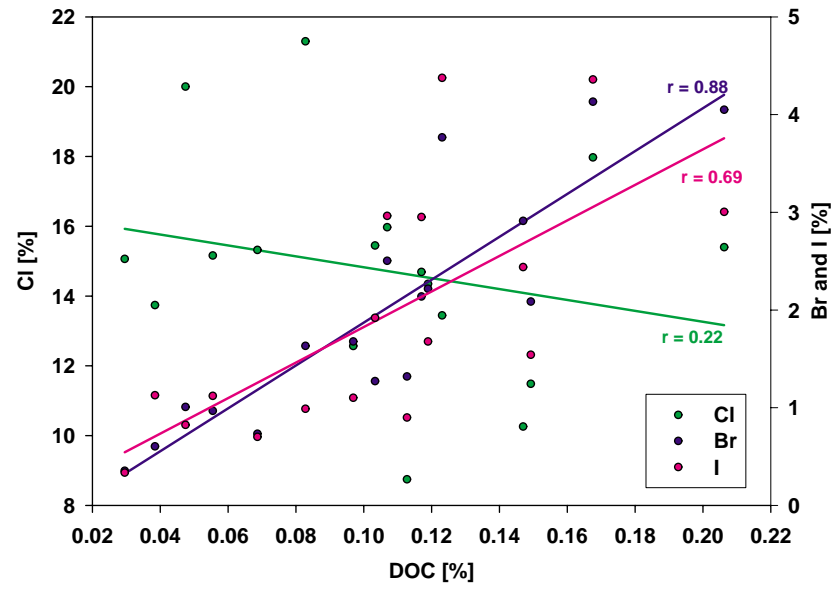

Fig. 5. Correlation between proportions of released halogens and DOC in pore water sampled at three ombrotrophic peat bogs GC1 (a), SKY (b), PBR (c) located in the Magellanic Moorlands.

Figure 5 shows the correlation between percentages of DOC and halogens released from peat at all three sites. It is evident that the release of bromine and iodine from peat is controlled by the release of halogenated DOC and that both 
parameters depend on the degree of peat decomposition. In the $\mathrm{GC} 1$ bog the similarity between the profiles of proportions of bromine, iodine or DOC release is again not pronounced, assumingly because of the low variability of the degree of peat decomposition (Fig. 4a). However, the large proportion of organobromine and organoiodine in the pore water of this bog (Table 1) indicates that both components are also associated with DOM.

Proportions of released chlorine appear to follow proportions of released DOC in some section of the three profiles, but this trend is weak if compared to bromine and iodine. Due to the assumingly small proportions $(<3 \%)$ of organically bound chlorine in the pore waters correlation of chlorine with DOC was not expected.

No direct dependency between proportions of released bromine and iodine, and proportions of released DOC could be observed if the three bogs are compared among each other. The bromine and iodine release from PBR peat is twice as high as from SKY peat, despite that the mean proportions of released DOC is almost the same (Table 1). Moreover, release of DOC is lowest in the GC1 bog, but the extent of bromine release is similar to what is found in the SKY bog, which show two times higher DOC release. The most likely explanation for this is that bromine or iodine concentrations in peat have influence on their concentrations in the released organohalogens (or the halogen concentration in released DOM). Mean total halogen concentrations are by a factor of 2-3 higher in GC1 peat than in the other two bogs and those in PBR peat are by $25-47 \%$ higher than in SKY peat (Table 1). The influence of bromine and iodine concentrations in peat on their concentrations in DOM is expressed by the DOC/organohalogen ratios in pore water. They are significantly lower in GC1 and PBR where halogen concentrations in peat are higher than in SKY peat independent from the amount of released DOC (Table 3). Proportions of released bromine and iodine are therefore controlled by two major factors, which are the amount of released DOM and their total concentrations in peat. The influence of both factors is largely determined by the degree of peat decomposition. Halogen concentrations will be high, but the release of DOC will be low, when peat is highly decomposed and the release of DOC will be high in relatively low decomposed peat but halogen concentrations will be relatively low. Due to the correlation between peat decomposition, released DOC and bromine and iodine it seems that the release of DOC is the predominant factor determining the extent of bromine and iodine release from peat in the catotelm.

\section{Conclusions}

Halogens were found to be strongly enriched in peat pore water if compared to rain water. The high enrichment factors (20-30 fold) found could not be explained by evapotranspiration alone. All halogens show steep concentration gra-
Table 3. Mean molar ratios of dissolved organic carbon (DOC) and organically bound bromine $(\mathrm{oBr})$ and iodine $(\mathrm{oI})$ in pore water sampled at the locations GC1, SKY, and PBR.

\begin{tabular}{ccc}
\hline & DOC/oBr & DOC/oI \\
\hline GC1 & 2214 & 37550 \\
Sky & 6965 & 54090 \\
Pbr & 2978 & 24540 \\
\hline
\end{tabular}

dients throughout the peat profile indicating that advection and diffusion are generally low and that halogen concentrations predominately reflect release from the peat substrate. Moreover, the observed relation between chemical parameters in peat and pore water indicates that the used sipping technique allows sampling of deep vertical profiles of pore water from individual peat sections, and that mixing effects during sampling can be mostly neglected. Mechanisms of halogen release from peat appear to differ between chlorine and bromine and iodine. Bromine and iodine in pore water mainly occur as soluble organohalogens, whereas the distribution of chlorine in pore water appears to be dominated by chloride. Release of bromine and iodine is generally low $(<2.5 \%)$ and seems to be mainly controlled by the release of DOM. Proportions of released DOC and bromine and iodine are influenced by the degree of peat degradation. Accordingly, the release of halogens from peat bogs has a strong climatic component (bog wetness) reflected by the degree of peat decomposition and the potential to release DOM. Following the concept of increased DOC release from peat bogs during wet and warm periods (Freeman et al., 2001), higher release rates of halogens, especially of bromine and iodine, have to be expected during such climatic conditions. We therefore postulate that the release of halogens will increase from those bogs where wetness increases under present day warming. On the other hand, climate warming may cause increasing frequency of drought events and dry falling of peatlands, which will diminish export of DOC and therefore also of halogens.

Acknowledgements. This work was funded by the Deutsche Forschungsgemeinschaft, grant BI 734 to H. Biester. Thanks to G. Öberg, C. Blodau and an unknown referee for their critical and helpful comments. We like to thank, C. Franzen and R. Kilian for their support during fieldwork.

Edited by: T. Laurila 


\section{References}

Appelo, C. A. J. and Postma, D.: Geochemistry, Groundwater and Pollution, Balkema Rotterdam, pp. 536, 1996.

Asplund, G., Grimvall, A., and Petterson, C.: Naturally produced adsorbable organic halogen (AOX) in humic substances from soil and water, Sci. Total Environ., 81/82, 239-248, 1989.

Asplund, G. and Grimvall, A.: Organohalogens in nature, Environ. Sci. Technol., 25, 1346-1350, 1991.

Asplund, G., Christiansen, J. V., and Grimvall, A.: A chloroperoxidase-like catalyst in soil: detection and characterization of some properties, Soil Biol. Biochem., 25, 41-46, 1993.

Bedard, D. L. and Van Dort, H. M.: Complete Reductive Dehalogenation of Brominated Biphenyls by Anaerobic Microorganisms in Sediment, Appl. Environ. Microbiology, 64, 940-947, 1998.

Bendell-Young, L. and Pick, F. R.: Base cation composition of pore water, peat and pool water of fifteen Ontario peatlands: implifications for peatland acidification, Water, Air and Soil Pollut., 96, 155-173, 1997.

Biester, H., Martinez-Cortizas, A., Birkenstock, S., and Kilian, R.: Historic Mercury Records in Peat Bogs - The Role of Peat Decomposition, and Mass Losses, Environ. Sci. Technol., 3, 32-39, 2003.

Berg, P., Risgaard-Petersen, N., and Rysgaard, S.: Interpretation of measured concentration profiles in sediment pore water, Limnol. Oceanogr., 43(7), 1500-1510, 1998.

Biester, H., Keppler, F., Putschew, A., Martinez-Cortizas, A., and Petri, M.: Halogen retention, organohalogens, and the role of organic matter decomposition on halogen enrichment in two Chilean peat bogs, Environ. Sci. Technol., 38, 1984-1991, 2004.

Bird, G. A. and Schwartz, W.: Distribution Coefficients $\mathrm{K}_{d} \mathrm{~s}$, for iodine in Canadian Shield Lake Sediments Under Oxic and Anoxic Conditions, J. Environ. Radioactivity, 35/3, 261-279, 1996.

Blodau, C. and Moore, T. R.: Macroporosity affects water movement and pore water sampling in peat soils, Soil Sci., 167, 98109, 2002.

Blodau, C. and Moore, T. R.: Experimental response of peatland carbon dynamics to a water table fluctuation, Aquat. Sci., 65, 47-62, 2003.

Chagué-Goff, C. and Fyfe, W.: Geochemical and petrographical characteristics of a domed bog, Nova Scotia: a modern analogue for temperate coal deposits, Organic Geochemistry, 24, 141-158, 1996.

Cornel, P. K., Summers, R. S., and Roberts, P. V.: Diffusion of Humic Acid in Dilute Aqueous Solution, J. Colloid and Interface Sci., 110, 149-164, 1986.

Dahlmann, O., Mörck, R., Ljungquist, P., Reimann, A., Johansson, C., Borén, H., and Grimvall, A.: Chlorinated Structural Elements in High Molecular Weight Organic Matter from Unpolluted Waters and Bleached-Kraft Mill Effluents, Environ. Sci. Technol., 27, 1616-1620, 1993.

Flodin, C., Johansson, E., Boren, H., Grimvall, A., Dahlman, O., and Mörck, R.: Chlorinated Structures in High Molecular Weight Organic Matter Isolated from Fresh and Decaying Plant Material and Soil, Environ. Sci. Technol., 31, 2464-2468, 1997.

Fraser, C. J. D., Roulet, N. T., and Lafleur, M.: Groundwater flow patterns in a large peatland, J. Hydrol., 246, 142-154, 2001.

Freeman, C., Evans, C. D., Monteith, D. T., Reynolds, B., and Fenner, N.: Export of organic carbon from peat soils, Nature, 412,
6849, 2001.

Heumann, K., Rädlinger, G., Erbes, M., Heiber, I., Obst, U., Filip, Z., and Claus, H.: Ageing of Dissolved Halogenated Humic Substances and the Microbiological Influence on this Process, Acta hydrochimica et hydrobiologica, 28, 193-201, 2000.

Ingram, H. A. P.: Size and shape in raised mire ecosystems: a geophysical model, Nature, 297, 300-303, 1982.

Ingram, H. A. P.: Hydrology, in: Ecosystems of the world, edited by: Gore, A. J. P., 4A. Mires: Swamp, bog, fen and moor, Elsevier, Amsterdam, Oxford, New York, p. 67-158, 1983.

Ivanov, K. E.: Water movements in mirelands, Academic Press, London, 276 pp., 1981.

Kalbitz, K. and Geyer, S.: Different effects of peat degradation on dissolved organic carbon and nitrogen, Organic Geochemistry, 33, 319-326, 2002.

Keppler, F. and Biester, H.: Peatlands: a major sink for naturally formed organic chlorine, Chemosphere, 52, 451-453, 2003.

Keppler, F., Biester, H., Putschew, A., Silk, P., Schöler, H. F., and Müller, G.: Organoiodine formation during humification in peatlands: a key process in terrestrial iodine cycling, Environ. Chem. Lett., 1, 219-223, 2004.

Kilian, R., Hohner, M., Biester, H., Wallrabe-Adams, C., and Stern, C. R.: Holocene peat and lake sediment tephra record from the southernmost Chilean Andes (53-55 S), Revista Geologica de Chile, 30, 2003.

Kuhry, P. and Vitt, D. H.: Fossil Carbon/Nitrogen ratios as a measure of peat decomposition, Ecology, 77, 271-275, 1996.

Malmer, N. and Wallén, B.: Accumulation and release of organic matter in ombrotrophic bog hummocks - processes and regional variation, Ecography, 16, 193-211, 1993.

Malmer, N. and Wallén, B.: Input rates, decay losses and accumulation rates of carbon in bogs during the last millenium: internal processes and environmental changes, The Holocene, 14, 111117, 2004.

Maw, G. A. and Kempton, R. J.: Bromine in soils and peat, Plant and Soil, 65, 103-109, 1982.

Öberg, G.: The natural chlorine cycle - fitting the scattered pieces, Appl. Microbiol. Biotechnol., 58, 565-581, 2002.

Putschew, A., Keppler, F., and Jekel, M.: Differentiation of the halogen content of peat samples using ion chromatography after combustion (TX/TOX-IC), Anal. Bioanal. Chem., 375, 781-785, 2003.

Rädlinger, G. and Heumann, K. G.: Transformation of Iodide in Natural and Wastewater Systems by Fixation on Humic Substances, Environ. Sci. Technol., 34, 3932-3936, 2000.

Romanowicz, E. A., Siegel, D. I., and Glaser, P. H.: Hydraulic reversals and episodic methane emissions during drought cycles in mires, Geology, 21, 231-234, 1993.

Sacher, F., Raue, B., and Brauch, H.-J.: Trace-level determination of bromate in drinking water by IC/ICP-MS, in: Disinfection byproducts in drinking water, edited by: Fielding, M. and Farrimond, M., The Royal Society of Chemistry, Cambridge, 91-97, 1999.

Schneider, C., Glaser, M., Kilian, R., Santana, A., Butorovic, N., and Casassa, G.: Weather observations across the Southern Andes at $53^{\circ} \mathrm{S}$, Physical Geography, 24, 97-119, 2003.

Shaw, P. D. and Hager, L. P.: Biological Chlorination IV. Peroxidative nature of enzymatic chlorination, J. Am. Chem. Soc., 81, 6527-6528, 1959. 
Shotyk, W.: Atmospheric deposition and mass balance of major and trace elements in two oceanic peat bog profiles, northern Scotland and Shetland Islands, Chemical Geology, 138, 55-72, 1997.

Siegel, D. I., Reeve, A. S., Glaser, P. H., and Romanowicz, E. A.: Climate-driven flushing of pore water in peatlands, Nature, 374, 531-533, 1995.

Silk, P. J., Lonergan, G. C., Arsenault, T. L., and Boyle, C. D.: Evidence of natural organochlorine formation in peat bogs, Chemosphere, 35(12), 2865-2880, 1997.

Steinmann, P. and Shotyk, W.: Chemical composition, $\mathrm{pH}$, and redox state of sulfur and iron in complete vertical pore water profiles from two Sphagnum peat bogs, Jura Mountains, Switzerland, Geochim. Cosmochim. Acta, 61, 1143-1163, 1997.

Succow, M. and Joosten, H.: Landschaftsökologische Moorkunde, E. Schweizerbart'sche Verlagsbuchhandlung, Stuttgart, pp. 622, 2001.
Van Pée, K.-H. and Unversucht, S.: Biological dehalogenation and halogenation reactions, Chemosphere, 52, 299-312, 2003.

Whitehead, D. C.: The distribution and transformations of iodine in the environment, Environ. Int., 10, 331-339, 1984.

Winterton, N.: Chlorine: the only green element - towards a wider acceptance of its role in natural cycles, Green Chemistry, 2, 173225, 2000.

Yuita, K.: Overview and Dynamics of Iodine and Bromine in the Environment, JARQ, 28, 90-99, 1994.

Zech, W., Senesi, N., Guggenberger, G., Kaiser, K., Lehmann, J., Miano, T. M., Miltner, A., and Schroth, G.: Factors controlling humification and mineralization of soil organic matter in the tropics, Geoderma, 79, 117-161, 1997. 